\title{
Development and Construction of Higher Education in China under Perspective of Lifelong Education
}

\author{
Wei Zhu ${ }^{1}$, Jiejuan Tang ${ }^{1 *}$, Yuzhou $\mathrm{Li}^{2}$ \\ ${ }^{1}$ Institute of Tourism, Henan normal university, Xinxiang, CHINA \\ ${ }^{2}$ Physical Culture Institute, Henan Normal University, Xinxiang, CHINA
}

Received 17 July 2017 - Revised 11 October 2017 - Accepted 13 November 2017

\begin{abstract}
The concept of lifelong education has four indicators: school education, social education, formal education and non-formal education. Under the concept of lifelong education, the concept of "higher education" can be summarized as four indicators, such as regular higher education, adult higher education, self-study higher education examination and distance network education. Foreign scholars consider that the concept of "higher education" is aimed at adults, which has little relevance with the concept of lifelong education. In China, the influence of concept of lifelong education on the construction and development of "higher education" is not proposed clearly. Based on the research status, SWT analysis method was introduced. The internal relation between the concept of lifelong education and the concept of higher education was analyzed through the four groups of corresponding relationship between internal advantage and external advantage. Through the detailed analysis of four groups of corresponding relationship such as the school education and regular higher education, the social education and adult higher education, the normal education and self-study higher education examination, the non-formal education and distance network education. The conclusion that the concept of lifelong education could promote the development and construction of concept of higher education in China was obtained. In the process of analyzing each component, the conclusion that the external variables also increased with the increase of internal variables could be obtained. Integrating the variation tendency of four components, the overall variation trend between concept of lifelong education and the concept of "higher education" was obtained. Through this analysis, blanks in our academic research are filled. The concept of lifelong education has a strong role in promoting the development and construction of the concept of higher education. Through a detailed analysis, we will find a better way to develop higher education.
\end{abstract}

Keywords: lifelong education, higher education, four indicators, SWT analysis method

\section{INTRODUCTION}

Lifelong education refers to the summation of all kinds of education that people receive in different stages of their lives. It is the unification and comprehensiveness of different types of education (Han, 2017; Neto and Wilks, 2017). It includes the all stages and various ways of education system, which not only has school education and social education, but also has formal education and non-formal education. It advocates to provide necessary knowledge and skill in the best way at the moment when everyone needs. The idea of lifelong education has become the guideline of educational reform in many countries. The terminology" lifelong education" was proposed in 1965 by Frenchman (Paul Lengrand), which has been widely spread in the world. Even so far there is no unified authoritative conclusion (Huang, 2015; Garvey, 2017). This fact not only reflects the level of concern of new educational idea, but also proves that there is the difference between comprehensive explanation and rigorous argumentation in the theory and practice (Guerrero and Roberts, 2017). 


\section{Contribution of this paper to the literature}

- Improve and perfect the relationship between the concept of lifelong education and the concept of "higher education", and point out the new development direction of "higher education".

- Lay the foundation of the concept of lifelong education on higher education.

- Fully study the relationship between the concept of lifelong education and the concept of "higher education", and prove the promotion relationship between the two.

The concept of "higher education" can be summarized as four items: regular higher education, adult higher education, self-study higher education self-examination and distance network education. In the concept of lifelong education, four indicators of concept of "higher education" in China have the corresponding relation with them. Where, school education corresponds to regular higher education, social education corresponds to adult higher education, formal education corresponds to self-study higher education examination, non-formal education corresponds to distance network education. The lifelong character, universalization, universality, flexibility and practicability are four characteristics of lifelong education. The lifelong character includes all stages and forms of education system. The universalization is a new subject in modern society which is proposed to everyone. The universality impregnates new activities for the whole education. The flexibility and practicability reflect that people choose the most suitable learning according to their own characteristics and needs (Plewa et al., 2015; Benham et al., 2017). Through the promotion of four indicators, the concept of lifelong education has gradually improved the development and construction process of the concept of higher education.

\section{LITERATURE REVIEW}

The "suggestion on development of adult education" was adopted in 1976 Nairobi conference. In the suggestion, adult education is a part of lifelong education. The education is not only confined to the stage of school education, but it should extend to all aspects of life and all areas of skills and knowledge. Under the influence of this lifelong education idea, governments of the world regard adult education as the forerunner for promoting lifelong education process, and they pay high attention to adult education, and make laws to ensure the development of adult education (Lo, 2016). In 1976, Norway was the first country in the world that adopted adult education, who regarded the adult education as the foundation of lifelong learning system. It promoted the coordination and cooperation among various fields of adult education. In 1982, the Republic of Korea enacted the social (adult) education law, and proposed the institutionalization of social (adult) education. In 1973, the education plan adopted by the Federal Republic of Germany ranked adult education as fourth kinds of education. In order to guarantee the implementation of adult education, many countries have taken many effective measures, such as: flexible policies in the entrance requirement; vacation with pay; economic aid; adult credit accumulation courses (Yang, 2017; Dresel et al., 2015; Ahmed et al., 2017).

From 1894 to 1911, it was the early phase of modern higher education in China. In the end of the 19th century, Tianjin Chinese and Western School, Nanyang Public School, Zhejiang Qiushi Academy and Imperial University of Peking are the prototypes of modern university. The "gui-mao school system" promulgated in 1904 includes" school rules approved by emperor", "higher school rules approved by emperor", "farm-industry-commerce industrial school rules approved by emperor". In these regulations, there is a new representation about the schoolrunning concept and training target: "to follow the imperial instruction, correct trend (Muller, 2015). In Chinese traditional education also stresses the "generalist". However, this "generalist" takes "grasp of academic art" as the premise, which is different with the ideal personality "generalists" of feudal education, and this goal promotes the position of "art" and "specialist" (Su, 2015). In a certain sense, the concept of western higher education is more accepted. Certainly, this "generalist" must “abide by decree" (Illeris, 2015; De Abreu et al., 2017).

\section{METHODS}

The development and construction of the concept of "higher education" in China under the concept of lifelong education is explored. SWT analysis method is used to establish the corresponding relationship between both components. SWT analysis method has two variables: internal advantage and external advantage, where the internal advantage is the master variable, and the external advantage is the following variable (Bevitt, 2015). For the premise that the internal advantage is constantly changing, the change rule of external advantage is analyzed. The concrete application method is shown in Figure 1 (LaChausse, 2017; Nwagu et al., 2017). 


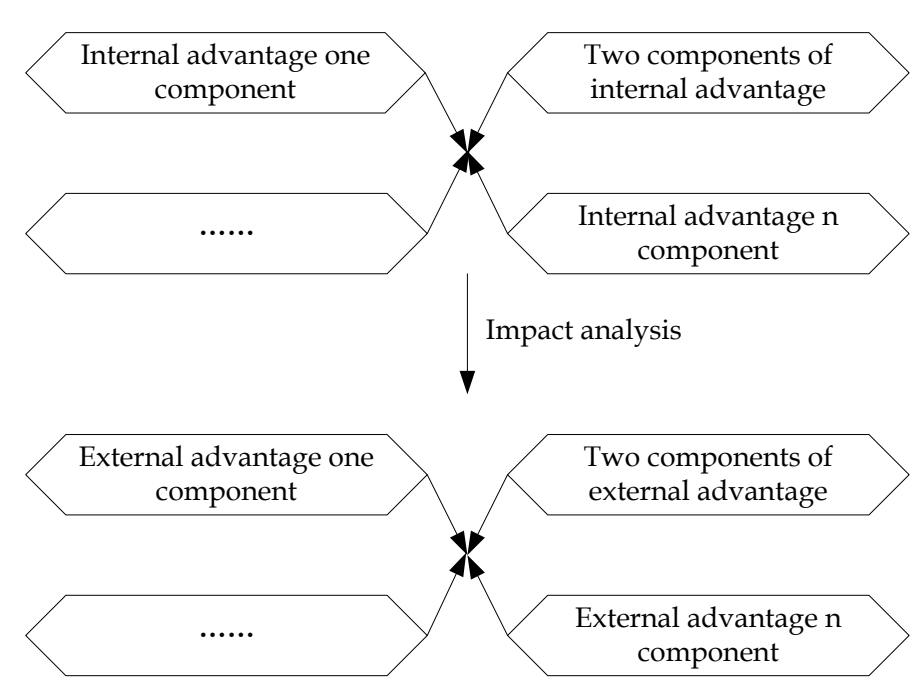

Figure 1. Detailed annotation of application of SWT analysis method

Table 1. Basic relationship between internal advantage component and external advantage component

\begin{tabular}{lll}
$\begin{array}{l}\text { Internal advantage } \\
\text { component }\end{array}$ & $\begin{array}{l}\text { External advantage } \\
\text { component }\end{array}$ & Basic relation \\
\hline School education & General higher education $\begin{array}{l}\text { With the improvement of school education, the level of ordinary higher } \\
\text { unchanged, the level of ordinary higher education remains unchanged }\end{array}$ \\
\hline Social education & Adult higher education & $\begin{array}{l}\text { With the improvement of social education level, the level of adult higher } \\
\text { education is also improved; when the level of social education remains } \\
\text { unchanged, the level of adult education remains unchanged }\end{array}$ \\
\hline Regular education & $\begin{array}{l}\text { Self-study higher } \\
\text { education examination }\end{array}$ & $\begin{array}{l}\text { With the improvement of formal education level, the self-taught higher } \\
\text { education examination is becoming more and more strict; when the level of } \\
\text { formal education remains unchanged, the self-taught higher education } \\
\text { examinations always remain the original state }\end{array}$ \\
\hline Informal education & $\begin{array}{l}\text { With the improvement of informal education, the number of online learning } \\
\text { users increases; when the level of non-formal education remains unchanged, } \\
\text { the number of remote network learning users remains unchanged }\end{array}$ \\
\hline
\end{tabular}

In this research, four impact indicators of lifelong education: schooling education, social education, formal education, non-formal education are taken as the four components in the internal advantage. Four impact indicators of higher education: regular higher education, adult higher education, self-study higher education examination, distance web-based learning are taken as the four components of external advantage (Crick et al., 2015) corresponding to internal advantage component. Generally, in SWT analysis, the internal advantage is expressed as $I_{a}$. The external advantage is expressed as $E_{a}$. and the specific relationship can be expressed as:

$$
\alpha=\sum_{i=1}^{i}\left\{\frac{\left[\left(I_{a i}-I_{a(i-1)}\right)+\left(I_{a(i-2)}-I_{a(i-3)}\right)+\cdots+\left(I_{a 2}-I_{a 1}\right)\right]}{\left[\left(E_{a i}-E_{a(i-1)}\right)+\left(E_{a(i-2)}-E_{a(i-3)}\right)+\cdots+\left(E_{a 2}-E_{a 1}\right)\right]}\right\}
$$

where, $\alpha$ denotes the change rule between the internal advantage and external advantage. $i$ denotes the number of corresponding relationship between the internal and external advantages. $I_{a 1}-I_{a i}$ denote the components of internal advantage from the first item to the $i t h . E_{a 1}-E_{a i}$ denote the components of external advantage from the first item to the ith. In this paper, the following researches are carried out at the premise that $i=4$.

\section{RESULTS}

SWT analysis method is used to analyze the development and construction of concept of higher education in China under the concept of lifelong education. Firstly, the basic relationship between four internal advantage components such as the school education, social education, formal education, non-formal education and the four external advantage components such as regular higher education, adult higher education, self-study higher education examination, distance web-based learning can be obtained, which is shown in Table 1 (Akre and Suris, 2017). 


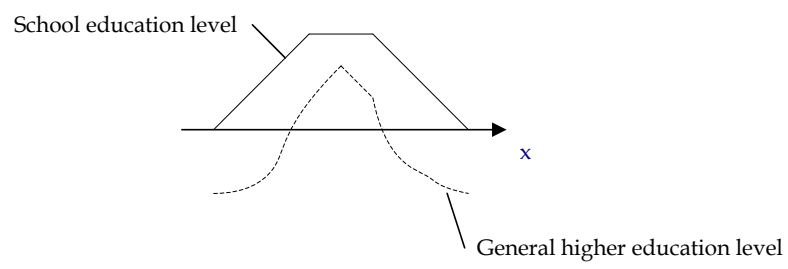

Figure 2. Relationship between level of school education and level of regular higher education

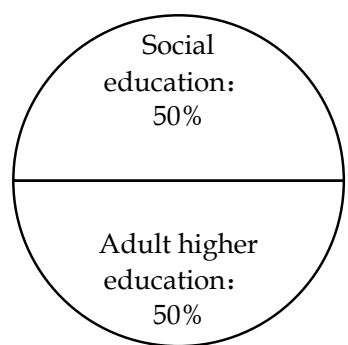

Initial state

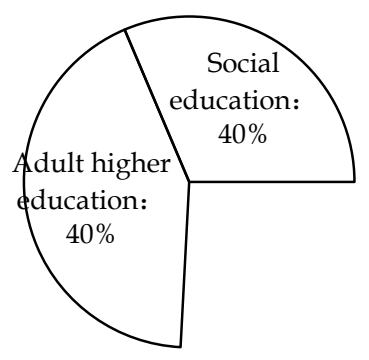

Decline stage

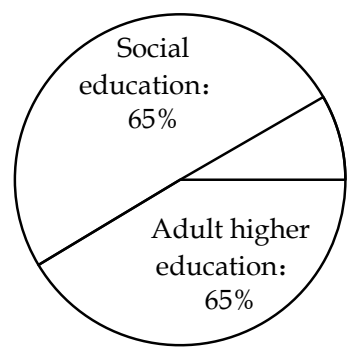

Rising phase

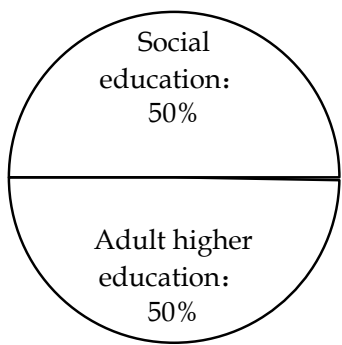

Remain unchanged

Figure 3. Relationship between level of social education and level of adult higher education

After determining the basic relationship between the internal advantage component and the external advantage component, the corresponding component in each group is analyzed separately. Then, following four sets of results can be obtained (John et al., 2017; Stylianides and Stylianides, 2017).

\section{School Education and Regular Higher Education}

The Figure 2 shows that when the level of school education shows a rising trend, the level of regular higher education also increases; when the level of school education shows a decreasing trend, the level of higher education also decreases; when the level of school education keeps unchanged, the level of regular higher education increases first and then decreases, but the range of reduction is the same as range of raise (Gabel and Dreyfus, 2017; Appelbaum and Appelbaum, 2017).

\section{Social Education and Adult Higher Education}

The Figure 3 shows that in the initial state, the level of social education and level of adult higher education keep a balanced state; when the level of social education shows a rising trend, the level of adult higher education also increases; when the social education level shows a decreasing trend, the level of adult higher education also decreases; when the level of social education keeps unchanged, the level of adult higher education will keep unchanged (Lawson et al., 2017; Kwon and Block, 2017).

\section{Formal Education and Self-Study Higher Education Examination}

From the analysis of Figure 4, in the initial state, the level of formal education is the same as the degree of strictness of self-study higher education examination; when the level of formal education shows a rising trend, the degree of strictness of self-study higher education examination also increases; when the level of formal education 


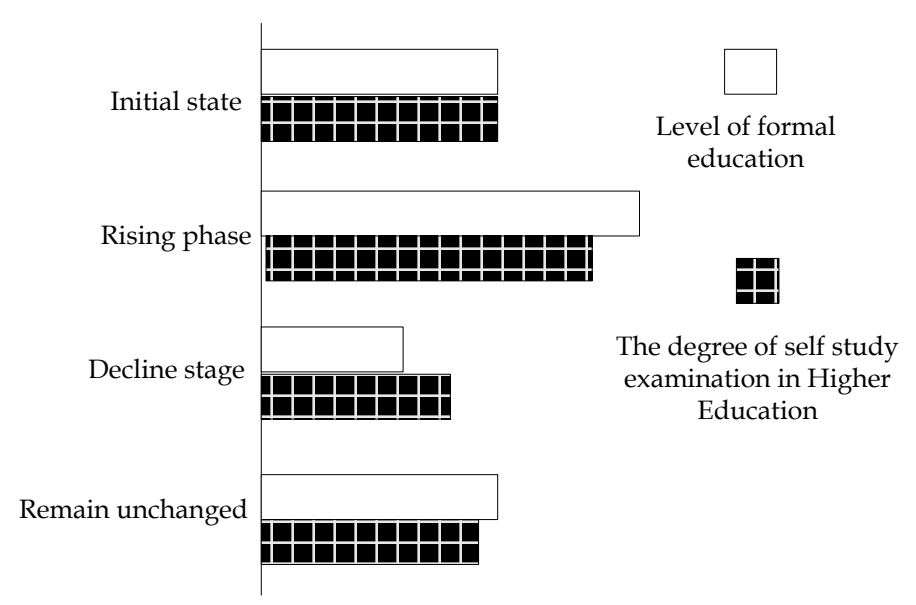

Figure 4. Relationship between level of formal education and degree of strictness of self-study higher education examination

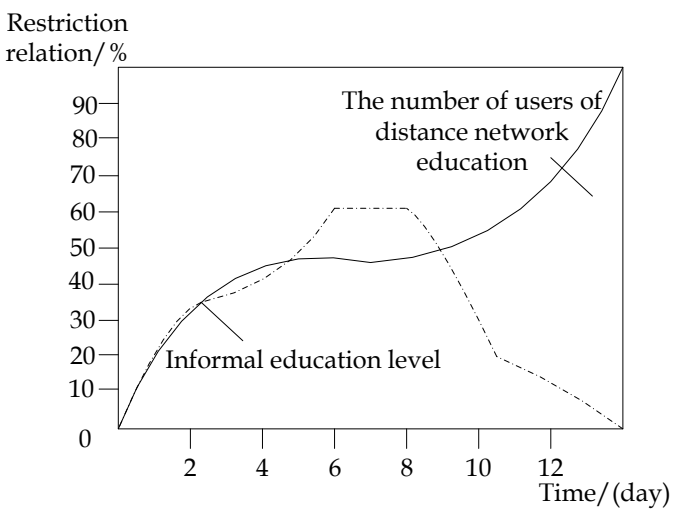

Figure 5. Relationship between level of non-formal education and number of users of distance network education

shows a decreasing trend, the degree of strictness of self-study higher education examination also decreases; when the level of formal education keeps unchanged, the degree of strictness of self-study higher education examination has declined slightly, but the range is not obvious, which can be neglected (John et al., 2017; Singh-Pillay and Sotsaka, 2017).

\section{Non-Formal Education and Distance Network Education}

The Figure 5 shows that when the level of non-formal education shows a rising trend, the number of users of remote network education increases; when the level of non-formal education shows a decreasing trend, the number of users of remote network education still increases; when the level of non-formal education keeps unchanged, the number of users of distance network education decreases first and then increases, and the range of increase reduction is very small, which can be neglected (Shilova and Sibgatullina, 2017).

Remote network education is geared to the public. With the development of society, people need to constantly charge themselves, and constantly improve their own quality, which lays the foundation for promoting life-long and popular education of remote network education. At the same time, the distance network education provides the basic condition for the improvement of the national quality. At present, the remote network education is developing towards the trend of intelligence and popularization. With the development of the remote network education, the education thought, education mode, education content and education structure will change significantly. The remote education has entered a rapid development period. The remote network education has its own advantages, mainly in the following aspects:

(1) Freedom of learning, breaking through the limitation of time and space;

(2) The introduction of multimedia, the forms of knowledge are more abundant;

(3) The non-linear knowledge structure facilitates learners to master their own learning progress and improves learners' learning efficiency; 
(4) Resources can be shared. The information transmitted on Internet constitutes a huge database, and learners can obtain all kinds of learning resources through the network;

(5) Interactivity is another characteristic of distance network education;

(6) Distance network education realizes the learner centered teaching model, which enables learners to have the autonomy of learning.

\section{DISCUSSION}

According to the analysis of relationship between internal advantage and external advantage, the change relationship between four sets of corresponding components can be obtained. On the basis of this relationship, we can carry out the following discussion.

(1) discussion of relationship between level of school education and level of regular higher education

The variation tendency in Figure 2 shows that there is a dynamic relationship between the level of school education and the level of regular higher education. When the level of school education increases, the level of regular higher education also increases, otherwise, it will decrease. When the level of school education keeps unchanged, the level of regular higher education increases first and then decreases, but the range of increase and decrease are the same, and the overall level keeps unchanged. Therefore, it can be considered that the level of school education is increased, which has a promoting effect on the level of regular higher education.

(2) discussion of relationship between the level of social education and the level of adult higher education

From the change of pie chart in Figure 3, there is a dynamic relationship between the level of social education and level of adult higher education. When the level of social education is increased, the level of adult higher education will increase, otherwise it will decrease. When the level of social education keeps unchanged, the level of adult higher education also keeps unchanged. Therefore, it can be considered that improving the level of social education can promote the level of adult higher education.

(3) discussion of relationship between the level of formal education and the degree of strictness of self-study higher education examination

Through the change of histogram in Figure 4, there is a dynamic relationship between the level of formal education and the degree of strictness of self-study higher education examination. When the level of formal education is increased, the degree of strictness of self-study higher education examination is improved, otherwise it will decrease. When the level of formal education keeps unchanged, the degree of strictness of self-study higher education examination decreases slightly, but the range is too small, which can be ignored. Therefore, improving the level of formal education can promote the degree of strictness of self-study higher education examination.

(4) discussion of relationship between the level of non-formal education and the number of users in distance network education

Through the variation tendency of curve in Figure 5, we can see that there is a stable relationship between the level of non-formal education and the number of users in distance network education. Regardless of whether the level of non-formal education increases or decreases, the number of users in distance network education always increases. When the level of non-formal education is unchanged, the number of users in distance network education has declined slightly, but the range is too small, which can be ignored, the overall trend still increases. Therefore, it can be considered that the increase of level of non-formal education promotes the number of users in the distance network education.

\section{CONCLUSION}

The above research shows that the lifelong education has four components. Four components of higher education are corresponding to it. Where, the level of school education, social education, formal education and nonformal education has a promotion effect on the level of regular higher education, the level of adult higher education, the degree of strictness self-study higher education examination and the number of users of distance network education. Thus, as the cornerstone of educational reform, the concept of lifelong education has the strong role for promoting the development and construction of concept of higher education. Comprehensively implementing the concept of lifelong education provides an outpouring of support for the development and construction of concept of "higher education" in China (Merrill, 2015).

\section{ACKNOWLEDGEMENT}

The National social science fund in 2017-The policy study on the promotion of students' physical health in China (No. 17BTY017); 
Key projects of philosophy and social sciences research in Henan Provincial Education Department in 2014 Financial support for the construction of Central Plains Economic Zone (No. 2014-ZG-003);

Doctoral program sponsored by Henan Normal University in 2015-Research on the development of rural tourism in China based on the beautiful rural construction (No. QD15150).

\section{REFERENCES}

Ahmed, N., Sadat, M., \& Cukor, D. (2017). Sleep Knowledge and Behaviors in Medical Students: Results of a Single Center Survey. Academic Psychiatry, 41(5), 674-678.

Akre, C., \& Suris, J. C. (2017). Adolescents and young adults' perceptions of electronic cigarettes as a gateway to smoking: a qualitative study in Switzerland. Health Education Research, 32(5), 448-454.

Appelbaum, N. P., \& Appelbaum, E. N. (2017). Getting real: preparing medical students and physicians for error disclosure. Medical Education, 51(10), 984-986.

Benham, A. L., Leikauf, J. E., \& Romanowicz, M. (2017). The Need for Infant Mental Health Training for All Child and Adolescent Psychiatrists. Academic Psychiatry, 41(5), 596-600.

Bevitt, S. (2015). Assessment innovation and student experience: a new assessment challenge and call for a multiperspective approach to assessment research. Assessment E Evaluation in Higher Education, 40(1), 103-119.

Crick, R. D., Huang, S., Shafi, A. A., \& Goldspink, C. (2015). Developing Resilient Agency in Learning: The Internal Structure of Learning Power. British Journal of Educational Studies, 63(2), 121-160.

De Abreu, I. D., Hinojosa-Lindsey, M., \& Asghar-Ali, A. A. (2017). A Simulation Exercise to Raise Learners' Awareness of the Physical and Cognitive Changes in Older Adults. Academic Psychiatry, 41(5), 684-687.

Dresel, M., Schmitz, B., Schober, B., Spiel, C., Ziegler, A., Engelschalk, T., .., \& Steur, G. (2015). Competencies for successful self-regulated learning in higher education: structural model and indications drawn from expert interviews. Studies in Higher Education, 40(3), 454-470.

Gabel, M., \& Dreyfus, T. (2017). Affecting the flow of a proof by creating presence-a case study in Number Theory. Educational Studies in Mathematics, 96(2), 187-205.

Garvey, J. C. (2017). Considerations for Queer as a Sexual Identity Classification in Education Survey Research. Journal of College Student Development, 58(7), 1113-1118.

Guerrero, A. P., \& Roberts, L. W. (2017). Snapshots from the Cutting Edge: Innovations in Child and Adolescent Psychiatry Training to Address Workforce Shortages. Academic Psychiatry, 41(5), 571-573.

Han, S. H. (2017). Institutionalization of Lifelong Learning in Europe and East Asia: from the Complexity Systems perspective. Asia Pacific Education Review, 2017(2), 1-14.

Huang, B. Z. (2015). Three practical modes of vocational education reflecting the concept of Lifelong Education: generative mechanism and problem solving. China Vocational and technical education, 19(33), 23-26.

Illeris, K. (2015). The Development of a Comprehensive and Coherent Theory of Learning. European Journal of Education, 50(1), 29-40.

John, A., \& Zapata Roblyer, M. (2017). Mothers Parenting a Child with Intellectual Disability in Urban India: An Application of the Stress and Resilience Framework. Intellectual and Developmental Disabilities, 55(5), 325-337.

John, M., Molepo, J. M., \& Chirwa, M. (2017). South african learners' conceptual understanding about image formation by lenses. EURASIA Journal of Mathematics, Science and Technology Education, 13(6), 1723-1736. doi:10.12973/eurasia.2017.00694a

Kwon, E. H., \& Block, M. E. (2017). Implementing the adapted physical education E-learning program into physical education teacher education program. Research in Developmental Disabilities, 69, 18-29.

LaChausse, R. G. (2017). A clustered randomized controlled trial to determine impacts of the Harvest of the Month program. Health Education Research, 32(5), 375-383.

Lawson, J. E., Cruz, R. A., \& Knollman, G. A. (2017). Increasing positive attitudes toward individuals with disabilities through community service learning. Research in Developmental Disabilities, 69, 1-7.

Lo, W. Y. W. (2016). The recalibration of neoliberalisation: repoliticising higher education policy in Hong Kong. Higher Education, 73, 1-15.

Merrill, B. (2015). Determined to stay or determined to leave? A tale of learner identities, biographies and adult students in higher education. Studies in Higher Education, 40(10), 1859-1871.

Muller, J. (2015). The future of knowledge and skills in science and technology higher education. Higher Education, 70(3), 409-416. 
Neto, F., \& Wilks, D. C. (2017). Predictors of Psychological Adaptation of Cape Verdean Students in Portugal. Journal of College Student Development, 58(7), 1087-1100.

Nwagu, E. N., Dibia, S. I. C., \& Odo, A. N. (2017). Socio-cultural norms and roles in the use and abuse of alcohol among members of a rural community in Southeast Nigeria. Health education research, 32(5), 423-436.

Plewa, C., Galán-Muros, V., \& Davey, T. (2015). Engaging business in curriculum design and delivery: a higher education institution perspective. Higher Education, 70(1), 35-53.

Shilova, Z. V., \& Sibgatullina, T. V. (2017). Methodology features of teaching stochastics to university students of the biology specialization. EURASIA Journal of Mathematics, Science and Technology Education, 13(8), 47254738. doi:10.12973/eurasia.2017.00960a

Singh-Pillay, A., \& Sotsaka, D. S. (2017). Engineering graphics and design teachers' understanding and teaching of assembly drawing. EURASIA Journal of Mathematics, Science and Technology Education, 13(5), 1213-1228. doi:10.12973/eurasia.2017.00668a

Stylianides, G. J., \& Stylianides, A. J. (2017). Research-based interventions in the area of proof: the past, the present, and the future. Educational Studies in Mathematics, 96(2), 119-127.

$\mathrm{Su}, \mathrm{Y}$. H. (2015). Targeting Assessment for Developing Adult Lifelong Learners: Assessing the Ability to Commit. Australian Journal of Adult Learning, 55(1), 75-93.

Yang, K., \& Ma, Q. (2017). Big data to improve the quality of distance education, extract effective resources simulation. Computer simulation, 34(04), 212-215.

\section{http://www.ejmste.com}

